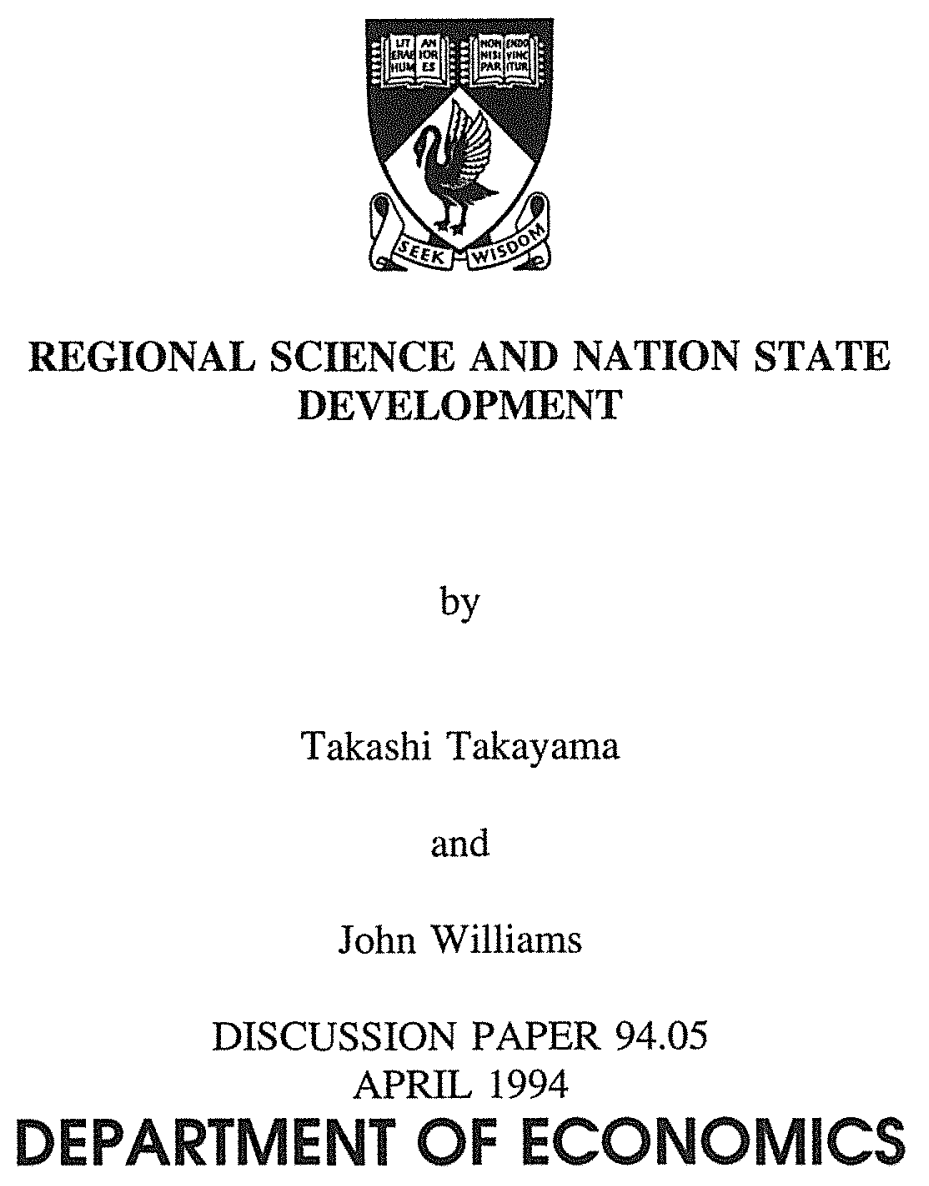

The University of Western Australia

Nedlands, Western Australia, 6009 


\title{
REGIONAL SCIENCE AND NATION STATE DEVELOPMENT
}

\author{
by \\ Takashi Takayama \\ Department of Economics \\ University of Western Australia \\ and \\ John Williams \\ Department of Economics \\ The University of Western Australia
}

DISCUSSION PAPER 94.05

APRIL 1994

ISSN 0811-6067

ISBN 0-86422-321-8

This paper was prepared for the International Conference on Regional Science in Developing

Countries, October 10-14, 1993, at Peking University, Beijing, China 


\section{Introduction}

China, it seems to us, is about to embark on an unprecedented transformation of its economy and society. Its economy is steadily opening up and establishing links with the rest of the world. We conjecture that this will have the effect of changing the form of the Chinese economy: as a result of its interaction with market oriented economies, the Chinese economy will itself become more market oriented.

A long-term projection such as this usually does not help national leaders and policy decision makers. The problems national leaders have faced throughout the course of the human history have been, more or less, intermediate to short-run in nature.

In this paper we first review some modern theories of economic development to establish an intermediate-run focus on the development of a nation state, and briefly present our own view on this subject. Secondly, a brief review of some regional science methodologies relevant to developing countries is presented, and this is followed by our views on them. Thirdly, our own comprehensive view of nation state development is presented using differential game theory.

The paper concludes with a discussion of the role of academic regional science approaches in nation state building.

\section{A Brief Review of Economic Development Theories}

Theories of economic development have their own unique historical and national backgrounds. Rostow's often cited Stages Theory (1960) can be said to be a unique product of thinking on economic policy popular in the USA in the period immediately after the Second World War and revitalised in the 1960s (the Kennedy and Johnson eras). According to Rostow, the (any national) economy starts in Stage I as a traditional society, moves to Stage II, the preconditioning for the next higher level, and takes off in Stage III. An economy that can self-sustain its growth drives itself to Stage IV, the society of maturity, and finally reaches Stage $\mathrm{V}$, the society of high mass consumption.

Looking back, most developed economies in the world seem to have passed through all five stages in the order observed by Rostow. However, the way in which individual countries have progressed through particular stages has differed.

Due to the fact that Rostow worked with aggregate national product and/or per capita GNP (or GDP) data, his stages theory lacks policy implications especially for preconditioning for successful take off.

Rostow's theory is a descriptive explanation of historical experience rather than a prescriptive theory of use to policy decision makers. 
Detailed studies followed using statistical analysis of sectoral data, import and export data, balance of payments and exchange rate data, etc. One outstanding example of this type of research is Pattern of Japanese Economic Development, edited by Kazushi Ohkawa and Miyoheé Shinohara (CT-Yale University Press, 1977. These studies naturally led researchers toward the so called 'Structurist Theory' of development. In the structurist approach changes in the structure of an economy (for example, in industrial sectors or labour force composition), and changes in government policies (for example, in import substitution or export promotion policies), were examined for their implications for the economy as a whole and, in particular, for their effects on GNP (GDP).

The structurists' influence on national government development policies has been substantial. Professor Hollis Chenery, Vice President of Policy and Research in the World Bank during the 1970s and now at Harvard, played a key role in the formulation. of policy for developing countries which promoted the structurist view of industrial sector development as first priority. ${ }^{1}$

Obviously, if national developmental planners focus only on GNP (GDP) growth and implement policies to attain this objective by promoting industrial development over and above agricultural sector development, the problem of poverty in developing countries will persist. Policy interventions leading to higher GNP accompanied by a widening of the gap between the rich and the poor have to be remedied through another type of government intervention, namely income equalisation policy.

Furthermore, development of the nation state must be considered more broadly. Development affects people whose welfare depends on both physical wellbeing (absolute? but quantifiable and comparable over time) and psychological wellbeing (relative and hard to quantify). A national development plan must take these two aspects of welfare into consideration and attempt to balance them carefully.

Within this development policy framework, let us now review some of the regional science tools potentially relevant to the development of China in the 21 st century.

\section{Strategic Review of Regional Science Tools}

Regional science draws on a number of fields or disciplines including economics, finance, management science, geography, urban and regional planning, mining (petroleum) engineering, civil (transport) engineering, sociology, and political science. Therefore, it is almost impossible for one professional to review all of its techniques and methods. In this section we review only some of the regional science tools, in particular tools developed by economists, that may prove useful for developing countries.

\footnotetext{
${ }^{1}$ See H.B. Chenery (1979). Structural Change and Development Policy. Baltimore: Johns Hopkins University Press.
} 


\subsection{Location of regional production centres}

In 1826 von Thünen, in his Der isolierte Staat, advanced one of the first systematic expositions of how economic activity would be located in space. He examined the particular case of farmers producing different crops for sale at a single market for agricultural commodities. Producers of each crop would bid rents for land equal to their total revenues from sale of the crop less the cost of inputs to production and less the cost of transporting the crop to market. Farmers producing crops which yielded the highest net revenues would be able to bid the highest rents and would obtain land closest to the market. The resulting locational equilibrium would be a series of annular regions concentric around the central market with production in each region specialised to a particular crop.

Von Thünen's original insight has now been fully exploited with the use of linear and non-linear programming methods to determine the optimal locations for different types of economic activities. If regional demand and supply quantities are known and fixed, the Koopmans-Hitchcock transportation cost minimisation problem can be set up and solved for optimal product flows between regions. The shadow prices generated provide a basis for determination of absolute market prices by a planning authority. The details are presented in Takayama and Judge, Spatial and Temporal Price and Allocation Models (STPAM hereafter). Various applications are discussed in Judge and Takayama (eds.), Studies in Economic Planning over Space and Time. ${ }^{2}$

This type of modelling has been widely used by international organisations such as OPEC, the World bank, and FAO, and by government agencies including the US Department of Energy and the Environmental Protection Agency. Even though the modelling structures were simple (LP or similar) the dimensions of these models were large. The OPEC LP models each had more than ten thousand equality and inequality constraints and variables. Models with such large dimensions take a very long time to solve even on modern computers. We believe that, given our current modelling capabilities, planning authorities should refrain from investing heavily in very large scale modelling exercises even though the temptation to do so may be extremely high.

\subsection{Determination of efficient production, consumption and interregional trade}

As the nation starts to develop its trade with the rest of the world, the volume of its exports is small and is limited by both its capacity to produce export goods and by domestic consumption (which will be intentionally discouraged in order to improve the balance of payments). Once the volume of exports rises to a level at which the country in question can influence prices in world markers, 'market-oriented' modelling can be used to determine efficient levels of production, consumption and interregional trade.

2 T. Takayama and G.G. Judge (1971). Spatial and Temporal Price and Allocation Models. Amsterdam: North-Holland. G.G. Judge and T. Takayama (eds.) (1973). Studies in Economic Planning over Space and Time. Amsterdam: North-Holland. See also T. Takayama (1979). "An Application of Spatial and Temporal Price Equilibrium Model to World Energy Modelling." Papers of the Regional Science Association, 41: 43-58. 
Market-oriented modelling strategies are comprehensively documented in Parts III, IV and V of STPAM. ${ }^{3}$

There is always a nagging problem in modelling of this type that the planning horizon is not clear because the models are static. One way of overcoming this problem is to create a multi-period model with each period being clearly defined as, say, one year. This strategy was developed in Part VI of STPAM and tried in Takayama's paper MarketOriented World Petroleum Modelling. ${ }^{4}$ In practical application model dimensionality is significantly increased and rapidly becomes too large for solution even in LP format. In quadratic (non-linear) programming or linear complementary programming format, the model dimensionality is severely limited (to say $500 \times 500$ or $1,000 \times 1,000$ ) on average main frame computers. This curse of dimensionality may be overcome with advances in computer technology. Anna Nagurney has recently reported that a super-computer could solve a ten commodity-ten region-ten time period model within ten or twenty minutes. ${ }^{5}$ Provided a modelling group has free access to high-powered computing facilities, market-oriented regional modelling can be used effectively to assist economic decision-makers in the market place or policy makers within government.

\subsection{Computable general equilibrium modelling}

In economic theory, general equilibrium has played a prominent role since the end of the Second World War, at least up until the 1970s when the world plunged into food and oil crises.

The structurist policy of promoting industrialisation over and above agricultural sector development discussed in Section 1 was based on partial equilibrium studies of various developing and developed economies. It could not guarantee that, by pushing industrialisation, a developing country would achieve a higher GNP. A more comprehensive, multi-sectoral approach to the formulation of development policy was required. It was provided by Dervis et al. in their book General Equilibrium Models for Development Policy. ${ }^{6}$ This work marked the beginning of the Chenery group's search for a more balanced trade policy-oriented methodology for development policy. A

3 Some early applications are documented in Takayama and Judge (1973) (see note 2). Later applications are partially documented in T. Takayama and W. Labys (1986), "Spatial Equilibrium Analysis", in Peter Nijkamp (ed.), Handbook of Regional and Urban Economics, Vol. 1 (Amsterdam: North-Holland). See also W. Labys, T. Takayama and N. Uri (1989), Quantitative Methods for MarketOriented Analysis over Space and Time, (Aldershot: Avebury), and O. Guvenen, et. al. (eds.) (1991), International Commodity Market Models; Advances in Methodology and Applications, (London: Chapman and Hall).

4 T. Takayama (1976). Market-Oriented World Petroleum Modelling. Department of Economics, University of Illinois, Venezuela Project Report, No. 9.

5 Anna Nagurney (1993). Network Economics. Kluwer.

6 K. Dervis et al. (1982). General Equilibrium Models for Development Policy. A World Bank Research publication. 
recent and interesting policy-oriented application of their approach is reported in a paper by Hewings and Gazel, Regional and Interregional Impacts of the US-Canada Free Trade Agreement. ${ }^{7}$

Recent advances in computer hardware and software allow sophisticated general equilibrium models (with the number of constraints and variables less than about 1,000 ) to be solved efficiently.

However, these models and the results obtained from them are difficult to evaluate. Neither in economic theory nor in its application has the problem of dynamics been satisfactorily resolved, and computable general equilibrium methods do not at this time resolve dynamic (equilibrium) issues.

One way of tackling the dynamic interaction of economic variables is through the use of simulation methods. Recent economic-demographic interaction studies pursued for the ILO and UNDP by Professor Bojan Popovic are based on simulation methods, and the interested reader is referred to his paper Dynamic Response Analysis for a Model with Seemingly Long Lags - A Case of Decentralised Development Policies in a Multiregional Economy. ${ }^{8}$

In their early general equilibrium models, World Bank researchers assumed that markets for resources and products worked in a perfectly competitive manner, without testing the validity of this assumption for the developing economies in which they were interested. Furthermore, national accounting data for these economies were incomplete, and therefore input/output coefficients and other structural parameters did not exist and had to be 'created' by the modellers.

More recent studies, such as that by Hewings and Gazel, have used data from developed countries. In consequence, the modelling is more sophisticated and detailed, but may not be immediately applicable to developing economies.

We conclude this brief review of modelling approaches potentially useful for the evaluation of economic development policy by noting that it overlooks a series of fundamental questions: For whom and for what specific purpose is the modelling being done?

7 G. Hewings and R. Gazel (1992). Regional and Interregional Impacts of the US-Canada Free Trade Agreement. Final Report to the Economic Development Commission, U.S. Department of Commerce. Read at the International Conference on "Trade, Knowledge and the Network Economy", December 1014, 1992, in Mallacoota, Victoria, Australia.

8 B. Popovic (1988). "Dynamic Response Analysis for a Model with Seemingly Long Lags - A Case of Decentralised Development Policies in a Multi-regional Economy". A paper read at the Annual Meeting of the Society for Economic Dynamics and Control, Tempe, Arizona, March 9-11, 1988. 


\section{Development of a Nation State}

As Rostow pointed out, a nation state starts from a traditional society, which conditions itself for take off, and becomes a vigorously growing (developing) economy if preconditioning (nurturing) is properly done.

What are the necessary conditions for take-off? There exist a number of diverse views on this issue but, in our view, the following three conditions are essential to a steady growth of the economy of a developing nation state:

- A spirit or willingness for development.

- Capital.

- A stable society (law and order).

At an early stage in the development of the Japanese economy (in the Meiji period), a ViceMinister in the Finance Ministry clearly stated these requirements as follows:

Which requirements should be considered as most important in the present efforts of the government in building Japanese industries: It can be neither capital nor laws and regulations, because both are dead things in themselves and totally ineffective. The Spirit/Willingness set both capital and regulations in motion ... . If we assign weights to these three factors with respect to their effectiveness, spirit/willingness should be assigned five parts, laws and regulations four, and capital no more than one part. ${ }^{9}$

Capital provides nourishment and the legal system shows how to maintain a state of health. Whether or not these measures can help the patient recover depends on his willingness to recover. ${ }^{10}$

This succinctly summarises the functional importance of spirit/willingness, capital and a stable social order to economic development, and indicates the interrelationships among them.

In the past the World Bank and other international organisations have placed a heavy weight on capital in implementing development programs. But, without the leadership of the government and of individuals within the developing country, leadership which identifies development priorities and directs the development effort, capital injected will most likely be wasted and the development effort will most likely fail.

This points to the fact that 'development' is not just 'economic development' but the development of the entire society and economy of a nation state. The following diagram shows the relationships between the three principal structural elements which define a nation

\footnotetext{
${ }^{9}$ Kogyo Iken (A Proposal for Economic Development), Vol. 18.

10 Kogyo Iken, Vol. 18, p. 436. The economy of Meiji japan at the time (1868-80) was in a state of chaos, with a high rate of inflation and a large number of government-run enterprises failing.
} 
state and their interactions with the same structural elements as they occur in the rest of the world.

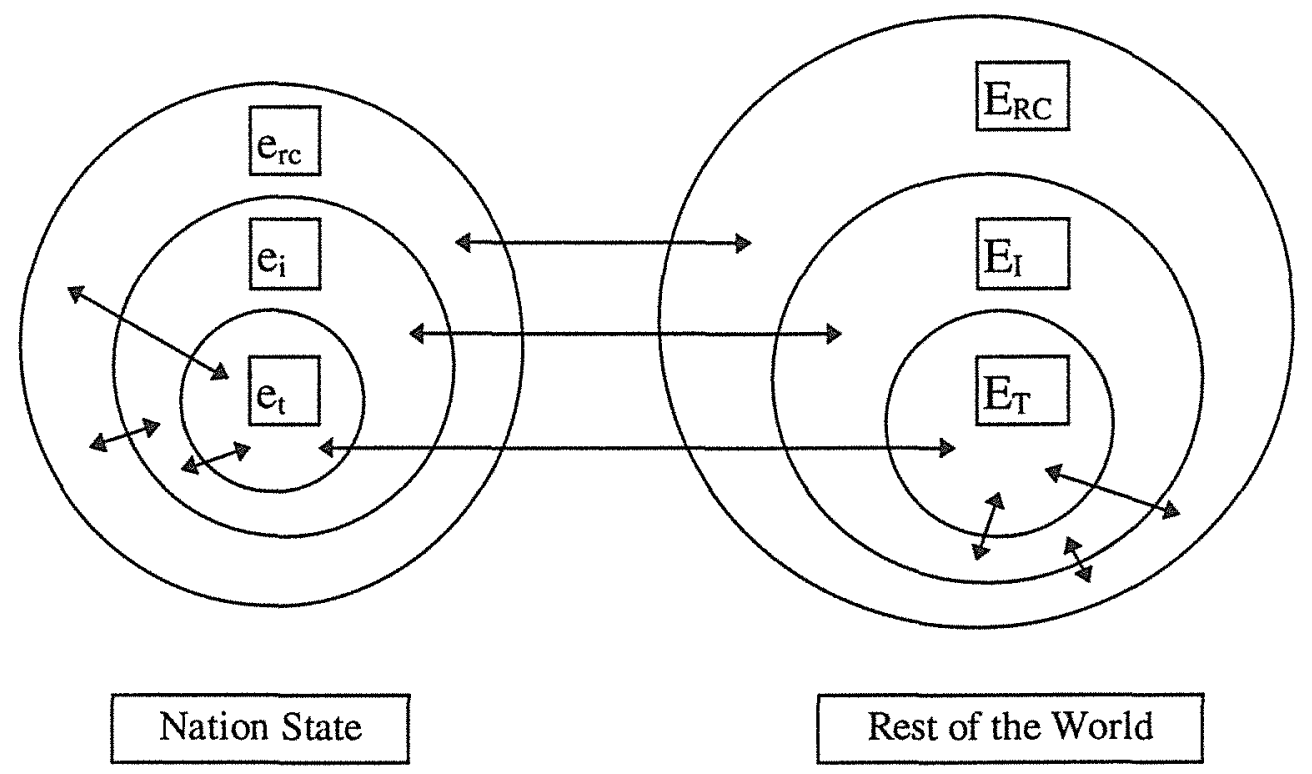

\section{Figure 1: Three Elements of Environment and Their Interaction}

$e_{t}, e_{i}$ and $e_{r c}$, and $E_{T}, E_{I}$ and $E_{R C}$ are the technological, institutional (constitutional, governmental, regulatory, educational, etc.), and religious-cultural environments of the developing country and the rest of the world respectively. These spheres of environment interact with each other both within and among countries.

If the national government is to lead the process of development, it must clearly identify the initial states of each environment. For instance, it must survey production technologies in each of the country's industries and compare them with technologies employed in the rest of the world. If superior foreign technologies can be transplanted, the implications of technology transfer must be carefully explored, the rate at which new technology is to be introduced decided upon, and appropriate policy implemented.

The institutional environment can also be changed to meet the challenge of economic development. Furthermore, it is conceivable that the government could initiate changes in the religious and cultural environment, but there is likely to be a long lag before these initiatives materially affect the society, even under direct pressure and threat from the rest of the world.

As national development proceeds, there must be close co-ordination and synchronisation of the development plans of the central government and regional governments. 
At this stage it is necessary to remind ourselves that a development plan is not created and superimposed by a third party (the rest of the world). It is the creation of national and regional leaders supported by the spirit/willingness of the people.

Having identified the three environments and the interactions among them, the interactions can be formalised in a system dynamics framework.

\section{System Dynamics in National and Regional Development}

Let $x(t), y(t)$, and $z(t)$ be vectors of (identified and ideally quantifiable) technologies, institutions, and religious-cultural factors, respectively. Each is defined over the period of a development plan, and each is a state vector. A national development plan aims at changing each of the components of these state vectors in a desired direction. Express the rates of change of the components of these state vectors as $\dot{x} \equiv d x / d t, \dot{y} \equiv d y / d t$, and $\dot{z}(t)=d z / d t$. Unless the nation state has a single tier of government, the national state vectors are aggregates (functions) of regional state vectors, say $x_{i}(t), y_{i}(t)$ and $z_{i}(t), i=1,2, \ldots, n$. We now write the time changes (dynamics) as follows:

$$
\begin{aligned}
\dot{x}(t) & =f(x(t), y(t), z(t), t) \\
\dot{y}(t) & =g(x(t), y(t), z(t), t) \\
\dot{z}(t) & =h(x(t), y(t), z(t), t)
\end{aligned}
$$

where $\quad x(t)=\left(x_{1}(t), x_{2}(t), \ldots, x_{n}(t)\right)^{\prime}, \quad y(t)=\left(y_{1}(t), y_{2}(t), \ldots, y_{n}(t)\right)^{\prime}, \quad$ and $z(t)=\left(z_{1}(t), z_{2}(t), \ldots, z_{n}(t)\right)^{\prime}$.

The change in technology is likely to be most rapid if the institutional environment has been made ready and if religion and culture do not stand in the way.

The dynamics of each of the regional vectors can be written:

$$
\begin{aligned}
& \dot{x}_{i}(t)=f_{i}\left(x(t), y(t), z(t), u_{i}(t), v_{i}(t), t\right) \\
& \dot{y}_{i}(t)=g_{i}\left(x(t), y(t), z(t), u_{i}(t), v_{i}(t), t\right) \\
& \dot{z}_{i}(t)=h_{i}\left(x(t), y(t), z(t), u_{i}(t), v_{i}(t), t\right)
\end{aligned}
$$

where $u_{i}(t)$ and $v_{i}(t)$ are the policy variable (control) vectors of the regional governments and the regionalised private sectors respectively.

The overall scheme of the development plan is integration of (central and regional) government plans with private sector plans in such a way as to meet certain national objectives set by government and also by the private sector. Let us write the government and private sector objective functionals as 
and

$$
\varphi(x, y, z, \dot{x}, \dot{y}, \dot{z}, u, v, t)
$$

$$
\psi(x, y, z, \dot{x}, \dot{y}, \dot{z}, u, v, t)
$$

respectively, where the time dimension of all vectors is dropped for simplicity, and $u$ and $v$ are aggregate government and private sector policy (control) vectors.

Given the system components defined above, we can represent the system dynamics of the development of a nation state as shown in Figure 2.

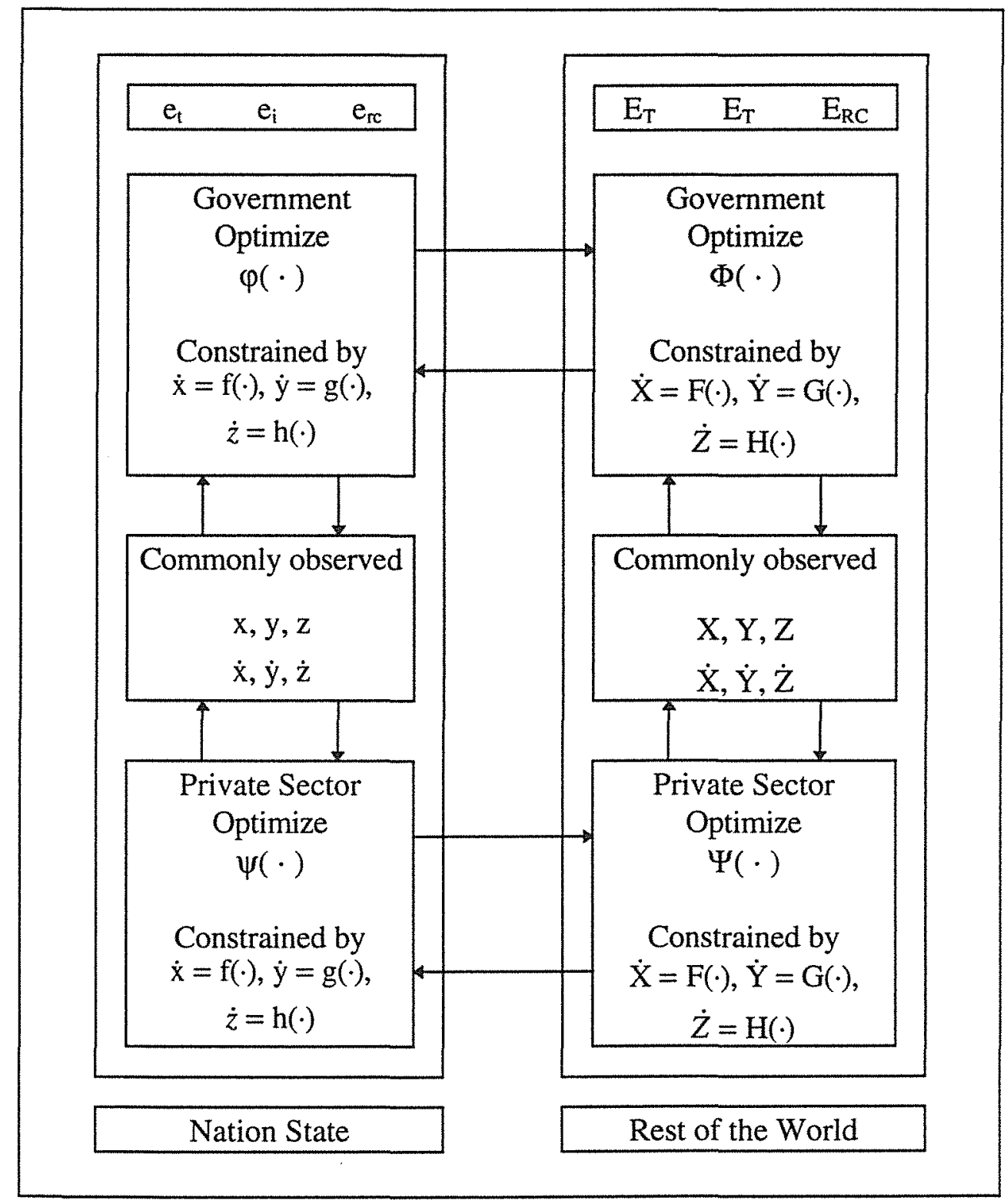

\section{Figure 2: Nation State and Rest of the World Interaction Differential Game Scheme}


The government sector carefully observes the regional dynamics of technology, institutions, and religion and culture, and then selects from among the policy options (control variables) that are available to it. In the early stages of national development only limited observations will be available on each of the three elements of the environment, and government can take a leadership role in creating the required data base (as the UN, the World Bank, and other international organisations have done in some cases). This data base is a set of records of the past, and is therefore a 'dead thing' by itself. Only the spirit/willingness of national and regional leaders to pursue development can put life into it. They are the ones who identify the dynamics of the three environments, $\dot{x}=f(\cdot), \dot{y}=g(\cdot)$ and $\dot{z}=h(\cdot)$, and influence them with their policy directives (controls), and make information (including the policy directives and national objectives) on the development process available to the private sector and to the people.

With a clear understanding of national and regional objectives and policies for the future, the private sector interacts with the government sector to attain its objectives after carefully observing the nation-wide dynamics. (This dynamic scheme is referred to as a differential game in Takayama's paper The Japanese Economy: Past, Present and Future. $^{11}$

This dynamic system cannot be closed to the rest of the world. In the early stages of national development, the evaluation of new technology and its introduction (if suitable), with the assistance of foreign engineers and specialists, is essential. Government to foreign government, government to foreign private sector, and finally private sector to foreign private sector interactions take place and usually in this order.

The right-hand block of Figure 2 shows the rest of the world counterpart of the system dynamics of the developing country. The dynamics of the rest of the world interact with the domestic dynamic system.

Technology development and transfer are taking place almost continuously throughout the world. National economic development requires intensive effort by the government and private sectors jointly to choose an optimal set of technologies to achieve development priorities currently and in the intermediate term. (The World Bank has played a key role in assisting a number of developing countries in this respect.)

At this stage in China's development, the role of leaders in government and in the private sector is of paramount importance in guiding the nation on a continuous path to prosperity.

National development is a process for which system dynamics in its time varying form provides a most suitable framework for analysis. As development progresses, the role of the private sector steadily expands and the government, with some resistance, relegates itself to a watchdog role.

11 T. Takayama (1988). "The Japanese Economy: Past, Present and Future." International Journal of Development Planning Literature, 3(4): 178-220). 


\section{Regional Science Methods in Nation State Development}

Regional science has drawn its methods and techniques from economics and from the other disciplines mentioned at the beginning of this paper. The focus of regional science research and its application have been largely issues and problems faced by highly developed modern economies in the last one-third of the twentieth century.

The issues and problems of developing countries have been tackled by international organisations including agencies of the United Nations and the World Bank. These organisations have developed their own strategies for research and its application, and have developed the data sets needed for their specific purposes. They have been concerned with bringing about structural change over time and, since the end of the Second World War, have assisted many countries with specific infrastructure development projects and with broader changes including the development of education systems. Cost-benefit analysis has been the principal tool employed in evaluating the options available. ${ }^{12}$ Its successful application requires more than the expertise of the economist.

The evaluation of a steel mill in China by a team of project specialists in the early 1980's provides an interesting example. Cost-benefit analysis was carried out along with other studies which investigated location of the mill in relation to the mine supplying raw material. These studies pointed to a potential bottleneck arising from the underdeveloped state of the transportation system between mine site and possible mill locations.

The analysis of infrastructure projects can be greatly improved with the adoption of a regional science perspective that combines the expertise of regional scientists trained in economics or geography with that of transport (highway) and mining engineers or others with expertise relevant to a particular project.

Most project evaluations have been performed by international (multi-national) consultancy firms, and many large development projects have been carried out by these firms, or consortia of these firms, supervised by international organisations. Ensuring that appropriate regional science expertise is brought to bear in project planning is recognised as one of the responsibilities of these supervising organisations.

Once a number of intermediate to large projects is completed and the development of industrial and commercial centres becomes self-sustaining, the speed of population movement from peripheral (usually rural) areas to these centres may not be controllable by the regional and/or national government.

12 A simple presentation is contained in L. Squire and H.G. von der Tak (1975). Economic Analysis of Projects. Baltimore: Johns Hopkins University Press. 
Issues such as the speed of population movement and its impact must be resolved by regional and national governments early in the process of economic development. In the next section we consider the critically important role of the nation (sovereign) state in the development process.

\section{Nation State Development and the Market Economy}

At this time in human history nobody can deny the existence of the nation (sovereign) state with its declared purpose of protection of its national borders and protection of its citizens. As industrialisation steadily advances international capital movements, in the form of public and/or private investments, permeate the borders of the nation state and, at least in some cases, gradually increase outsiders' control of the national economy.

It is desirable for developing nations to have freer trade arrangements with the market economies of the West, such as the United States, Japan, and the economies of Western Europe, to facilitate structural change and speed up the process of development. In the 1950 's freer trade was thought to contribute to the equalisation (relatively and absolutely) of factor prices (including wages and land rents) among trading nations. However, at that time, this may have been a statement about politics rather than economics as is clear from the following statement by Samuelson: "Thus, writing before the Marshall Plan and at a time when many were despairing of Europe's future, I was led by my factor-price model to make the diffident suggestion that moving goods by trade might be able to do nearly as much for living standards as moving Europeans to Australia or elsewhere". ${ }^{13}$ By altering labour mobility rather severely after the Second World War, the victors' strategy based on the factor price equalisation argument has worked, trickling its effects through the international economy.

New independent nation states sprang up in the 1950's, and new national borders have been declared - and disputed. On the world map a number of borders have been redrawn many times.

After the collapse of the communist system of the (former) USSR, the role of the national and regional governments in a freer market-oriented economic system should be re-examined. It is a fundamental proposition of liberal individualism that the smaller the government (the regulator) the better for individuals in the society.

In 1949 Dr Ludwig von Mises published his monumental work Human Action, in which he declared liberal individualism to be the very source of 'positive' human action in society, and discussed a wide range of issues and problems the world faced shortly after the Second World War. What logical conclusions can be drawn with respect to the nation state from the premises liberal individualism? Von Mises argues:

13 Paul A. Samuelson (1964). "Theory and Realism: A Reply." American Economic Review, LIV(5): 736-739. 
It is certainly true that our age is full of conflicts which generate war. However, these conflicts do not spring from the operation of the unhampered market society. It may be permissible to call them economic conflicts because they concern that sphere of human life which is, in common speech, known as the sphere of economic activities. But it is a serious blunder to infer from this appellation that the source of these conflicts are conditions which develop within the frame of a market society. It is not capitalism that produces them, but precisely the anticapitalistic policies designed to check the functioning of capitalism. They are an outgrowth of the various governments' interference with business, of trade and migration barriers and discrimination against foreign labor, foreign products and foreign capital.

None of these conflicts could have emerged in an unhampered market economy. Imagine a world in which everybody were free to live and work as entrepreneur or as employee where he wanted and how he chose, and ask which of these conflicts could still exist. Imagine a world in which the principle of private ownership of the means of production is fully realized, in which there are no institutions hindering the mobility of capital, labor, and commodities, in which the laws, the courts, and the administrative officers do not discriminate against any individual or group of individuals, whether native or alien. Imagine a state of affairs in which governments are devoted exclusively to the task of protecting the individual's life, health, and property against violent and fraudulent aggression. In such a world the frontiers are drawn on the maps, but they do not hinder anybody from the pursuit of what he thinks will make him more prosperous. No individual is interested in the expansion of the size of his nation's territory, as he cannot derive any gain from such an aggrandizement. Conquest does not pay and war becomes obsolete. $^{14}$

In such an idealistic state of the world, as von Mises argues, there is no need for national borders or for the nation state itself. However, in reality some or all of the fundamental prerequisites for this conclusion are not fulfilled, even in the Unites States of America from which von Mises derived his inspiration.

As long as nation states exist, the fundamental prerequisites for liberal individualism may be met to a greater or lesser extent within their borders. Von Mises considers the basic motive forces behind vigorous growth (development) of the economy to be i) a market economy, and ii) liberal individualism. He argues:

In the market economy the individual is free to act within the orbit of private property and the market. His choices are final. For his fellow men his actions are data which they must take into account in their own acting. The coordination of the autonomous actions of all individuals is accomplished by the operation of the market. Society does not tell a man what to do and what not to do. There is no need to enforce cooperation by special orders or

${ }^{14}$ Ludwig von Mises (1949). Human Action. Yale University Press. Pp. 680-681. 
prohibitions. Non cooperation penalises itself. Adjustment to the requirements of society's productive effort and the pursuit of the individual's own concerns are not in conflict. Consequently no agency is required to settle such conflicts. The system can work and accomplish its tasks without the interference of an authority issuing special orders and prohibitions and punishing those who do not comply. ${ }^{15}$

The only reason why the market economy can operate without government orders telling everybody precisely what he should do and how he should do it is that it does not ask anybody to deviate from those lines of conduct which best serve his own interests. What integrates the individual's actions into the whole of the social system of production is the pursuit of his own purposes. In indulging in his "acquisitiveness" each actor contributes his share to the best possible arrangement of production activities. Thus, within the sphere of private property and the laws protecting it against encroachments on the part of violent or fraudulent action, there is no antagonism between the interests of the individual and those of society. ${ }^{16}$

What would be the ultimate state of society if such blatant individualism were exercised in every sphere of activity? We do not know the answer to this question as the premises on which it is based have never been satisfied in human history. Nor can we fully agree with von Mises on the nature and function of government:

It is important to remember that government interference always means either violent action or the threat of such action. Government is in the last resort the employment of armed men, of policemen, gendarmes, soldiers, prison guards, and hangmen. The essential feature of government is the enforcement of its decrees by beating, killing, and imprisoning. Those who are asking for more government interference are asking ultimately for more compulsion and less freedom.

To draw attention to this fact does not imply any reflection upon government activities. In stark reality, peaceful social cooperation is impossible if no provision is made for violent prevention and suppression of antisocial action on the part of refractory individuals and groups of individuals. One must take exception to the often repeated phrase that government is evil, although a necessary and indispensable evil. What is required for the attainment of an end aimed at is a means, the cost to be expended for its successful realisation. It is an arbitrary value judgment to describe it as an evil in the moral connotation of the term. However, in face of the modern tendencies toward a deification of government and state, it is good to remind ourselves that the old Romans were more realistic in symbolizing the state by a bundle of rods with

15 Ibid., p. 720.

16 Ibid., pp. 720-721. 
an axe in the middle than are our contemporaries in ascribing to the state all the attributes of God. ${ }^{17}$

The passage above shows von Mises' extremist view - his sheet distrust of government, which may have been associated with his begin driven out of Vienna by the Nazis, spending some years in Geneva (1934-1940), and finally finding himself at home in New York, the most cosmopolitan city in the USA (1940-1949, when Human Action was published). If he had had the chance to live in present day New York, he may have wished for more 'law and order' from local governments, and from state and Federal Governments, especially in dealing with the social decay associated with such issues as crime and drugs of addiction.

In East Asia, each of the sovereign states carries within itself over a thousand of years of history, religion and culture which work as constraints or bounds on the actions of individuals. Individual freedom has been more or less balanced by the individual's recognition of her/his social responsibilities, and the economic growth of these nation states has become an object of envy for the rest of the world.

The further national development progresses, the more visible becomes the grip of capitalism and liberal individualism. In dynamic systems terminology, the faster moving system $x$ influences the institutional system $y$, and eventually influences the religiouscultural system $z$. This latter effect may be very gradual, or it may be sudden as is the case when there is a change in ideology.

How long does it take for a system of nation states to disintegrate completely into a borderless society? In our view this could happen, as von Mises postulated, only if:

... everybody were free to live and work as entrepreneur or as employee where he wanted and how he chose... ${ }^{18}$

Given the tentative conclusions above, we argue that China's development policy cannot be a 'laissez faire' (or 'market economy') policy in its purest form. The national government should play a leading and guiding role as it has done in Japan since the Meiji Restoration. Facing more open market economies, the Government of China must accelerate the speed of industrialisation of all the sectors of the economy at a much higher rate than Japan has ever experienced. Government sponsorship of infrastructure development, in particular of highways, railways and the internal air transport system, will be essential to national development. Without improvements in transport, development may well remain confined to centres along the country's eastern seaboard. At the same time, China must maintain law and order in a one billion plus population distributed over roughly ten million square kilometres of its territory. This is a challenge that no nation state in the history of mankind has ever accepted.

\footnotetext{
17 Ibid., p. 715 .

18 Ibid., p.681.
} 
To succeed in nation state development, the Government of the Peoples' Republic of China must exert its own cumulative intelligence and wisdom in controlling the speed of adjustment in the three elements of environment, technology, institutions and religion and culture.

\section{Concluding Remarks}

The relationship between Regional Science and Nation State Development is discussed in this paper. The paper commenced with a short review of development economics, and then proceeded with a review of some practical methods which have been used during the last two decades, principally by international organisations, in the formulation of development policy. We then argued that a clear recognition of the nation state is of the utmost importance as the integrating core of economic development.

The development scheme of a nation state may be conceptualised as a dynamic system closely connected with the dynamics of the rest of the world. There is a great concern that, within this global dynamic system, nation state development may become a secondary priority if governments relinquish control of economies and allow the fullest operation of 'the market', that is, if they allow laissez faire in its purest form. A short review of von Mises' ideas on liberal individualism and the market economy leads us to conclude that, as long as completely free movement of labour is not realised, the nation state must continue to play a major role in the process of development.

National and regional governments must then demonstrate leadership and positively assist the private sector in creating a prosperous future for the nation. In this process regional science will play an important role in the formulation of policy for regional development and nation building. 